\title{
Porcine sperm capacitation involves tyrosine phosphorylation and activation of aldose reductase
}

\author{
Yuki Katoh ${ }^{1,2}$, Kohsuke Takebayashi ${ }^{1}$, Akihiko Kikuchi ${ }^{1}$, Ayumi Iki $^{1}$, Kazuhiro Kikuchi ${ }^{3}$, \\ Michiko Tamba ${ }^{1}$, Akihiro Kawashima ${ }^{1}$, Manabu Matsuda ${ }^{1}$ and Naomichi Okamura ${ }^{1,4}$ \\ ${ }^{1}$ Graduate School of Comprehensive Human Sciences, University of Tsukuba, Tennodai 1-1-1, Tsukuba, Ibaraki \\ 305-8575, Japan, ${ }^{2}$ Center for Humanities and Sciences, Ibaraki Prefectural University of Health Sciences, Ami 4669-2, \\ Ami, Ibaraki 300-0394, Japan, ${ }^{3}$ Division of Animal Sciences, National Institute of Agrobiological Sciences, Tsukuba, \\ Ibaraki 305-8602, Japan and ${ }^{4}$ Graduate School of Science, University of Tokyo, Tokyo 113-0033, Japan
}

Correspondence should be addressed to N Okamura; Email: naooka@md.tsukuba.ac.jp

\begin{abstract}
Mammalian sperm must be activated in the tubal isthmus through capacitation to induce the acrosome reaction and subsequent fertilization. Although the molecular mechanisms involved in capacitation have yet to be fully elucidated, increased concentrations of reactive oxygen species (ROS) and the extent of tyrosine phosphorylation of proteins have been suggested to play central roles in the completion of capacitation. In this study, aldose reductase was for the first time identified as one of the tyrosine-phosphorylated proteins involved in the capacitation of porcine cauda epididymal sperm. Both tyrosine phosphorylation and activity of aldose reductase associated with the particulate fraction of sperm cells were significantly enhanced during capacitation. Alrestatin, a membranepermeable and specific inhibitor of aldose reductase, plays a role in the inhibition of aldose reductase activity, elevation of intracellular levels of ROS, and induction of hyperactivated motility, all at similar dose dependencies. Alrestatin canceled both the increase in the tyrosine phosphorylation of aldose reductase and the decrease in the glutathione levels in sperm-induced during capacitation. The hyperactivated motility was induced to a higher extent in the presence of glucose than in the presence of fructose. These results indicate that aldose reductase plays an important role in induction of hyperactivation and capacitation of sperm through the elevation of ROS in sperm cells. Furthermore, aldose reductase was shown to be added to sperm during transit through the epididymis, suggesting that aldose reductase is one of the key proteins that support the functional maturation of sperm.
\end{abstract}

Reproduction (2014) 148 389-401

\section{Introduction}

Mammalian sperm require time-dependent changes in the female reproductive tract to acquire the capacity to fertilize oocytes; this acquisition is termed as 'capacitation' (Yanagimachi 1994, Fraser 2010, Aitken \& Nixon 2013). Capacitation involves modulation of cell membrane properties and signaling cascades, which results in the hyperactivation of motility and the acquisition of capacity to undergo the acrosome reaction (Gadella \& Harrison 2000, Harrison \& Gadella 2005, Salicioni et al. 2007). Several studies have suggested that both generation of reactive oxygen species (ROS) and tyrosine phosphorylation of proteins play essential roles in the process of capacitation (Visconti et al. 1995, 2002, Leclerc et al. 1996, Lewis \& Aitken 2001, O'Flaherty et al. 2006a, b, de Lamirande \& O'Flaherty 2008).

ROS such as superoxide anion $\left(\mathrm{O}_{2} \cdot{ }^{-}\right)$and nitric oxide $\left(\mathrm{NO}{ }^{*}\right)$ are produced at the initial step of capacitation and regulate the downstream events leading to hyperactivation and the acrosome reaction (de Lamirande \&
O'Flaherty 2008). NO • is produced by NO synthases, which have been found in both the head and the flagellar regions of sperm (Hou et al. 2008, de Lamirande et al. 2009). On the other hand, the source of $\mathrm{O}_{2}{ }^{-}$ production has yet to be fully elucidated, although $\mathrm{NAD}(\mathrm{P}) \mathrm{H}$ oxidase has been indicated as the enzyme responsible for its production in sperm during capacitation (Bedard \& Krause 2007, Sabeur \& Ball 2007, de Lamirande \& Lamothe 2009).

The polyol pathway contributes to diabetes-induced oxidative stress (Chung et al. 2003, Giacco \& Brownlee 2010). In particular, aldose reductase, the first and rate-limiting enzyme of the polyol pathway, has been suggested to be the major contributor to hyperglycemia-induced oxidative stress in nerve cells (Vikramadithyan et al. 2005). As the oviductal fluids, where sperm undergo capacitation, contain higher levels of glucose than of fructose (Larose et al. 2012), glucose flux through the polyol pathway is likely to increase in capacitating sperm, resulting in the induction of oxidative stress. In preliminary experiments, aldose 
reductase in porcine sperm was found to be tyrosinephosphorylated during capacitation. This finding prompted us to analyze the effects of aldose reductase activity on capacitation. Herein, we report that tyrosine phosphorylation and activation of aldose reductase are involved in porcine sperm capacitation in vitro, which are in turn inhibited by a specific and membranepermeable aldose reductase inhibitor, alrestatin.

\section{Materials and methods}

\section{Animals and chemicals}

All animal experiments were approved by the Animal Experiment Committee of the University of Tsukuba.

Fresh porcine testes and epididymes were purchased from the local slaughter house. Alrestatin was obtained from Enzo Life Sciences (Farmingdale, NY, USA). Lysyl endopeptidase, NADPH, DTNB, glutathione (GSH) reductase, and 6-carboxy-2', $7^{\prime}$ dichlorodihydrofluorescein diacetate, diacetoxymethyl ester $\left(\mathrm{H}_{2}\right.$ DCFDA $)$ were purchased from Wako Pure Chemical Industries (Osaka, Japan). GSH was purchased from Tokyo Chemical Industry (Tokyo, Japan). Chlortetracycline (CTC), peroxidase-conjugated anti-mouse $\lg \mathrm{G}$ antibody, peroxidaseconjugated anti-rabbit IgG, Freund's complete adjuvant, and Freund's incomplete adjuvant were obtained from SigmaAldrich. Protein A Sepharose 4 Fast Flow, ECL plus, and PreScission Protease were purchased from GE Healthcare (Chalfont St Giles, Buckinghamshire, UK). Protease Inhibitor Cocktail, Phosphatase Inhibitor Cocktail, and Chemi-Lumi One L were obtained from Nacalai Tesque (Kyoto, Japan). A sorbitol dehydrogenase (SORD) inhibitor, CP-470,711, was kindly donated by Pfizer. All other chemicals were reagent grade.

\section{Preparation of cauda epididymal sperm and induction of capacitation}

Spermatozoa were collected from the porcine cauda epididymis by air perfusion through the ductus epididymidis and washed at $20{ }^{\circ} \mathrm{C}$ with a noncapacitating medium (Non-cap medium) containing $4.8 \mathrm{mM} \mathrm{KCl}, 1.2 \mathrm{mM} \mathrm{KH}_{2} \mathrm{PO}_{4}, 95 \mathrm{mM}$ $\mathrm{NaCl}, 2 \mathrm{mM}$ sodium pyruvate, and $5.56 \mathrm{mM}$ glucose $(\mathrm{pH} 7.4)$ by centrifugation at $400 \mathrm{~g}$ for $5 \mathrm{~min}$. The sperm pellets were washed twice more with the Non-cap medium by centrifugation as mentioned above. When capacitation was induced, the Cap medium: $2 \mathrm{mM} \mathrm{CaCl}, 0.4 \% \mathrm{BSA}$, and $25 \mathrm{mM}$ $\mathrm{NaHCO}_{3}$ in the Non-cap medium, was used for washing the sperm pellets. The sperm forward motility was immediately determined under the microscope by the addition of Non-cap medium containing $25 \mathrm{mM} \mathrm{NaHCO}$. Only sperm samples with over $95 \%$ of the sperm showing progressive motility were used for the experiments. Sperm capacitation was induced according to the method reported by of Tardif et al. (2001), with slight modifications. The washed sperm were incubated either in $15 \mathrm{ml}$ of Non-cap medium or in Cap medium $\left(5 \times 10^{6} \mathrm{cell} / \mathrm{s} / \mathrm{ml}\right)$ at $37^{\circ} \mathrm{C}$ for $3 \mathrm{~h}$ in a $5 \% \mathrm{CO}_{2}$ atmosphere. Capacitated sperm were assessed on the basis of the changes in the pattern of the CTC fluorescence staining, according to the method of Wang et al. (1995).
Sperm motility was observed under the microscope, and the percentages of sperm with hyperactivated motion in all of the motile sperm were calculated. Sperm suspensions of $20 \mu \mathrm{l}$ $\left(1 \times 10^{5}\right.$ cell $\left.\mathrm{s} / \mathrm{ml}\right)$ prepared before and after capacitation were placed on a prewarmed $\left(37^{\circ} \mathrm{C}\right)$ slide and analysis of sperm motility was done using a computer-assisted sperm analysis (CASA) system (HTM-CEROS; Hamilton Thorne Research, Beverly, MA, USA) (Fig. 1a). Motion parameters such as curvilinear velocity $(\mathrm{VCL} ; \mu \mathrm{m} / \mathrm{s})$, straight-line velocity (VSL; $\mu \mathrm{m} / \mathrm{s})$, average path velocity (VAP; $\mu \mathrm{m} / \mathrm{s})$, linearity of the curvilinear trajectory (LIN; VSL $\times 100 / \mathrm{VCL}$ ), straightness (STR; VSL $\times 100 / V A P)$, amplitude of lateral head displacement (ALH; $\mu \mathrm{m})$, and beat cross-frequency $(\mathrm{Hz})$ were determined. For flagellar movement analyses, sperm motility was recorded by Nikon-NY-D5100 Super System (Microscope Network, Saitama, Japan) on the slide glass with $0.02 \mathrm{~mm}$ depth (Hamilton Thorne Research), and both the flagellar beat angle (FBA) and the flagellar curvature ratio (FCR) were determined according to the method of Schmidt \& Kamp (2004), as shown in Supplementary videos 1 and 2, see section on supplementary data given at the end of this article and Fig. 1b.

\section{Western blotting analysis of tyrosine-phosphorylated proteins}

Total sperm proteins were extracted with $1 \%$ Triton $\mathrm{X}-100$ in homogenizing buffer $(20 \mathrm{mM}$ Tris- $\mathrm{HCl}, \mathrm{pH} 7.4$, containing $2.5 \%$ Protease Inhibitor Cocktail and $0.25 \%$ Phosphatase

(a)
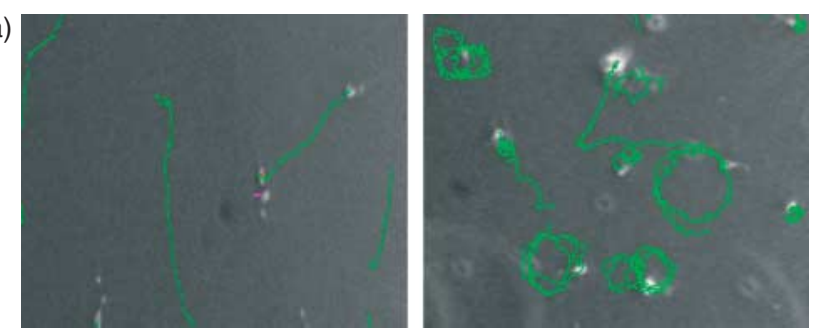

(b)
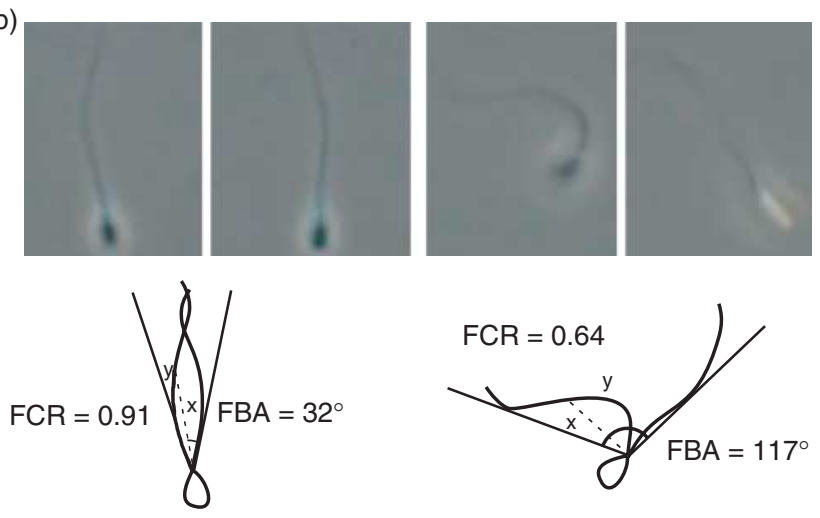

Noncapacitated sperm

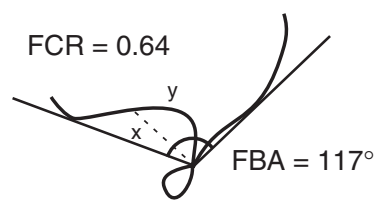

Capacitated sperm

Figure 1 Analysis of sperm motility. (a) Comparison of swimming trajectories obtained with CASA (frame rate $30 \mathrm{~Hz}$, frame acquired 80) between noncapacitated (left) and capacitated sperm (right).

(b) Representative flagellar movement of noncapacitated (left) and capacitated sperm (right) and determination of FBA and FCR. FBA and FCR values \pm S.E.M. $(n=10)$ of noncapacitated and capacitated sperm are given in the text. 
Inhibitor Cocktail) and separated either by SDS-PAGE or by two-dimensional gel electrophoresis (2-DE), according to a previously published method (Kawashima et al. 2009). The proteins were electroblotted to PVDF membranes under semidry conditions. The membranes were incubated with $100 \mathrm{mM} \mathrm{NaCl}, 0.1 \%$ Tween 20, $10 \mathrm{mM}$ Tris- $\mathrm{HCl}$ (pH 7.4) (TBST) containing $3 \% \mathrm{BSA}$ at $4{ }^{\circ} \mathrm{C}$ overnight by gentle mixing. After three washes with TBST, the membranes were treated with anti-phosphotyrosine MAB (BD Biosciences, San Jose, CA, USA) in TBST containing $1 \%$ BSA at $37^{\circ} \mathrm{C}$ for $60 \mathrm{~min}$. After three washes with TBST, the membranes were incubated with peroxidase-conjugated anti-mouse IgG antibody at $37^{\circ} \mathrm{C}$ for $60 \mathrm{~min}$ and then washed three times with TBST. The signals were detected through incubation of the membranes either with ECL plus or with Chemi-Lumi One L.

For the western blotting analysis of aldose reductase, antialdose reductase antisera prepared as indicated below and a peroxidase-conjugated anti-rabbit IgG were used as the first and secondary antibodies respectively. Sperm and fluid were collected from various regions of porcine epididymis according to the method of Dacheux et al. (1989) with slight modification. In brief, the ductus epididymidis in caput, corpus, and cauda regions was microperfused with air and the perfusate was collected. Testicular fluid and sperm were obtained by collecting the liquid contained in the rete testis duct. The perfusate was centrifuged at $500 \mathrm{~g}$ for $5 \mathrm{~min}$ at $20^{\circ} \mathrm{C}$. The supernatant was centrifuged again at $9000 \mathrm{~g}$ for $15 \mathrm{~min}$ at $4{ }^{\circ} \mathrm{C}$ and the supernatant was obtained as fluid. The sperm pellet was suspended with the Non-cap medium and washed twice by centrifugation at $1000 \mathrm{~g}$ for $5 \mathrm{~min}$ at $4{ }^{\circ} \mathrm{C}$. The resulting pellet was used for protein extraction.

\section{Identification of tyrosine-phosphorylated proteins}

The spots on the 2-DE gels corresponding to those detected by anti-phosphotyrosine MAB were analyzed by mass spectrometry, according to a previously described method (Osman et al. 2011).

For protein identification, monoisotopic masses of digested peptides observed in the MALDI-mass spectrometry spectra were used to query NCBInr and SWISS-PROT sequence databases using the Mascot search program (Matrix Science, London, UK; http://www.matrixscience.com).

\section{Production of antisera against aldose reductase}

Aldose reductase cDNA (nucleotides 121-971, accession no. AK398724) synthesized by RT-PCR using porcine testis DNase 1-treated total RNA as a template was ligated into the multicloning site (BamHI-Xhol) of pGEX-6P-2 and transformed into Escherichia coli DH5 $\alpha$. Oligonucleotides, 5'-GTGCTCTACACCGGATCCAAGATGCCCATC- $3^{\prime}$ and $5^{\prime}$-AGGCACAGACCCTCGAGTTCCTGTTGTAGC-3', were used as primers. Denaturation was carried out at $94{ }^{\circ} \mathrm{C}$ for $30 \mathrm{~s}$, annealing at $58{ }^{\circ} \mathrm{C}$ for $30 \mathrm{~s}$, and synthesis at $72{ }^{\circ} \mathrm{C}$ for $2 \mathrm{~min}$. The recombinant aldose reductase-GST fusion protein was bound to $\mathrm{GSH}-$ Sepharose $4 \mathrm{~B}$ beads and aldose reductase was cut out from GST using PreScission Protease, according to the manufacturer's instructions. The beads were centrifuged at
$1200 \mathrm{~g}$ for $10 \mathrm{~min}$, and the supernatant fraction was obtained as purified recombinant aldose reductase, which was detected as a single band by Coomassie Brilliant Blue (CBB)-staining after $2 \mu \mathrm{g}$ protein of the fraction had been separated on the SDS-PAGE gel and used as the antigen. Rabbit antisera against aldose reductase were prepared by s.c. injection of $200 \mu \mathrm{g}$ of antigen with Freund's complete adjuvant, followed by five additional booster injections of $400 \mu \mathrm{g}$ of antigen in Freund's incomplete adjuvant given at 1-week intervals.

\section{Immunoprecipitation}

Five hundred microliters of total sperm proteins ( $1 \mathrm{mg}$ protein) extracted as described before were incubated with $10 \mu \mathrm{l}$ of Protein A resin equilibrated with $20 \mathrm{mM}$ Tris- $\mathrm{HCl}(\mathrm{pH} \mathrm{7.4)} \mathrm{at}$ $4{ }^{\circ} \mathrm{C}$ for $90 \mathrm{~min}$ and then centrifuged at $2500 \mathrm{~g}$ for $10 \mathrm{~min}$ at $4{ }^{\circ} \mathrm{C}$. Next, $450 \mu \mathrm{l}$ of the supernatant was incubated with $50 \mu \mathrm{l}$ of preimmune sera or anti-aldose reductase antisera at $4{ }^{\circ} \mathrm{C}$ for $120 \mathrm{~min}$. Twenty microliters of Protein $\mathrm{A}$ resin was added to the mixture and then incubated at $4{ }^{\circ} \mathrm{C}$ for $90 \mathrm{~min}$. Protein $\mathrm{A}$ resin was precipitated by centrifugation at $2500 \mathrm{~g}$ for $10 \mathrm{~min}$ at $4{ }^{\circ} \mathrm{C}$ and washed three times with $0.1 \%$ Triton-X 100 in 20 mM Tris$\mathrm{HCl}(\mathrm{pH} 7.4)$ by centrifugation. The precipitated immune complexes were then denatured and resolved by SDS-PAGE for further western blotting analysis.

\section{Immunohistochemical analysis}

The porcine testes were fixed in Bouin's fluid and then dehydrated and embedded in paraffin. The sections $4 \mu \mathrm{m}$ in size were deparaffinized, soaked in $0.1 \mathrm{M}$ sodium citrate buffer $(\mathrm{pH} 6.0)$ at $90{ }^{\circ} \mathrm{C}$ for $30 \mathrm{~min}$, and washed with distilled water. The sections were successively incubated at room temperature with 3\% BSA in PBS (blocking buffer) and with anti-aldose reductase antisera in the blocking buffer for $60 \mathrm{~min}$ each. After three washes with PBS, signals were detected using a VECTASTAIN ABC Kit according to the manufacturer's instructions (Funakoshi Corporation, Tokyo, Japan).

\section{Determination of aldose reductase activity}

Aldose reductase activity was determined according to the method of Kador et al. (1980). In brief, $2.5 \times 10^{7}$ of sperm were homogenized by sonication in $5 \mathrm{ml}$ of $20 \mathrm{mM}$ Tris- $\mathrm{HCl}(\mathrm{pH}$ 7.4) with or without $1 \%$ Triton X-100 by means of an ULTRA $S$ homogenizer (TAITEC, Saitama, Japan) at the maximum output and centrifuged at $105000 \mathrm{~g}$ for $60 \mathrm{~min}$ at $4{ }^{\circ} \mathrm{C}$. The supernatant obtained in the presence of Triton X-100 was directly used to determine the aldose reductase activity ('whole sperm extract'). The supernatant obtained in the absence of Triton X-100 was finally supplemented with $1 \%$ Triton X-100 ('soluble fraction') and used for the enzyme assay. The precipitate obtained in the absence of Triton X-100 was suspended in $5 \mathrm{ml}$ of $1 \%$ Triton $\mathrm{X}-100$ in $20 \mathrm{mM}$ Tris- $\mathrm{HCl}$ (pH 7.4), incubated for $60 \mathrm{~min}$ at $4{ }^{\circ} \mathrm{C}$ with periodic vortexing, and centrifuged at $105000 \mathrm{~g}$ for $60 \mathrm{~min}$ at $4{ }^{\circ} \mathrm{C}$. The resulting supernatant was collected as the 'particulate fraction'. Two hundred microliters of these supernatants were incubated with $0.15 \mathrm{mM}$ NADPH and $10 \mathrm{mM}$ DL-glyceraldehyde in $120 \mathrm{mM}$ 
phosphate buffer $\left(\mathrm{pH}\right.$ 6.2) at $20^{\circ} \mathrm{C}$ for $10 \mathrm{~min}$, and the absorbance at $340 \mathrm{~nm}$ was monitored.

\section{Determination of ROS and GSH concentrations}

The concentrations of ROS in the sperm were determined according to the method of Awda et al. (2009) with slight modifications. Fifty micromolars of $\mathrm{H}_{2}$ DCFDA was added to the mixture at $150 \mathrm{~min}$ of the incubation for the induction of capacitation. The mixture was incubated for a further $30 \mathrm{~min}$, and sperm were collected by centrifugation at $400 \mathrm{~g}$ for $5 \mathrm{~min}$. The sperm pellet was suspended in the Non-cap medium and washed twice by centrifugation as mentioned above. The fluorescence of sperm at $530 \mathrm{~nm}$ in response to $488 \mathrm{~nm}$ excitation (Carter et al. 1994) was observed under the fluorescence microscope and evaluated using a microplate reader (Varioskan; Thermo Fisher, Yokohama, Japan).

The concentration of GSH in sperm was determined as described by Vandeputte et al. (1994) using a Total Glutathione Quantification Kit (Dojindo Laboratories, Kumamoto, Japan). Before and after the incubation for capacitation, the washed sperm $\left(5.3 \times 10^{7}\right.$ cells) were homogenized in $0.5 \mathrm{ml}$ of $5 \%$ sulfosalicylic acid and centrifuged at $8000 \mathrm{~g}$ for $10 \mathrm{~min}$ at $4{ }^{\circ} \mathrm{C}$. Twenty microliters of the supernatant was incubated at $20^{\circ} \mathrm{C}$ for $10 \mathrm{~min}$ with $200 \mu \mathrm{l}$ of $104 \mathrm{mM} \mathrm{NaH}{ }_{2} \mathrm{PO}_{4}, 4.6 \mathrm{mM}$ EDTA ( $\mathrm{pH} 7.4$ ) containing $1 \mathrm{mM}$ DTNB and $0.34 \mathrm{mM}$ NADPH. Then, $40 \mu \mathrm{l}$ of $\mathrm{GSH}$ reductase $(1.2 \mathrm{IU} / \mathrm{ml})$ was added to the incubation mixture, and after $10 \mathrm{~min}$, the absorbance was measured at $412 \mathrm{~nm}$ using the Varioskan.

\section{Statistical analyses}

Data were expressed as the means \pm s.E.M.s of at least three experiments. Statistical significance was calculated by twoway ANOVA. The difference between two means was determined by $t$-test, and differences among more than two means were determined by Tukey's test. The general linear models of Statistical Analysis System (SAS, Inc., Cary, NC, USA) were used for these analyses. Differences were considered significant at $P<0.05$.

\section{Results}

\section{Evaluation of capacitation and hyperactivation}

The sperm were incubated in Cap medium, and capacitation was induced, as assessed by the CTCfluorescence staining pattern of the sperm head (Wang et al. 1995, Tardif et al. 1999). Under the conditions of the present experiment, over $70 \%$ of the sperm represented pattern B fluorescence (fluorescence-free band in the postacrosomal region), thus proving them to be capacitated sperm (Fig. 2). FBA and FCR were determined as shown in Fig. 1b. The average values of FBA and FCR shifted from $42.7^{\circ} \pm 1.6$ and $0.89 \pm 0.009$ in noncapacitated sperm to $146.1^{\circ} \pm 8.8$ and $0.59 \pm 0.02$ in capacitated sperm respectively. Those values of capacitated sperm satisfied the threshold values of FBA

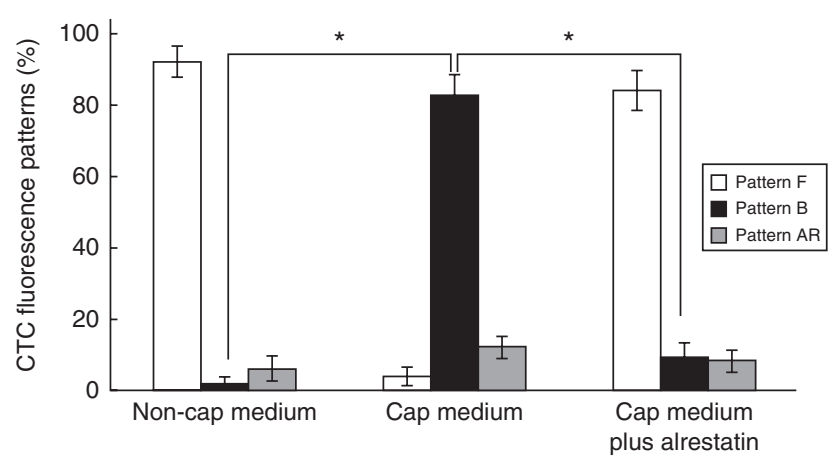

Figure 2 Effect of alrestatin on the change in CTC-fluorescence staining pattern. The patterns of CTC-fluorescence staining was determined on sperm cultured either in Non-cap medium or in Cap medium in the absence or the presence of $500 \mu \mathrm{M}$ alrestatin. The percentage of sperm stained in either F, B, or AR pattern was assessed. Noncapacitated sperm: pattern $F$, capacitated sperm: pattern $B$, and acrosome reacted sperm: pattern AR, were indicated by open, closed, and gray bars respectively. Data are expressed as mean \pm s.E.M. from six determinations. ${ }^{*} P<0.001$.

$\left(87^{\circ}\right)$ and FCR $(0.7)$ for those of boar sperm hyperactivated in the presence of the $\mathrm{Ca}^{2+}$ ionophore $\mathrm{A}$ 23187 (Schmidt \& Kamp 2004).

\section{Identification of aldose reductase as a tyrosine phosphoprotein phosphorylated during capacitation of porcine cauda epididymal sperm}

The sperm proteins were extracted by sonicating the sperm with the homogenizing buffer containing $1 \%$ Triton X-100, separated by 2-DE, and analyzed by western blotting for phosphorylation of the tyrosine residues as described in the 'Materials and methods' section. Using MALDI-TOF-MS analysis, we identified three tyrosine phosphoproteins phosphorylated during capacitation (Fig. 3 and Table 1). Aldose reductase (spot 3 in Fig. 3) was for the first time identified as a tyrosine phosphoprotein. The identified peptide fragments covered $42 \%$ of the whole amino acid sequences of aldose reductase (Fig. 4), and the Mascot score (118) was significant enough for the identification (Table 1).

Antisera against aldose reductase were prepared using the purified recombinant protein as the antigen, which contained all the fragments identified by MALDI-TOFMS analysis. The antisera recognized only the spot identified as aldose reductase by MALDI-TOF-MS analysis (Fig. 3g). Increase in the tyrosine phosphorylation of aldose reductase during capacitation (Fig. 3d and e) was confirmed by western blotting analysis of the immunoprecipitated aldose reductase (Fig. 3h).

\section{Intracellular localization of aldose reductase in the capacitated sperm}

To analyze the intracellular localization of aldose reductase, the cauda epididymal sperm were 

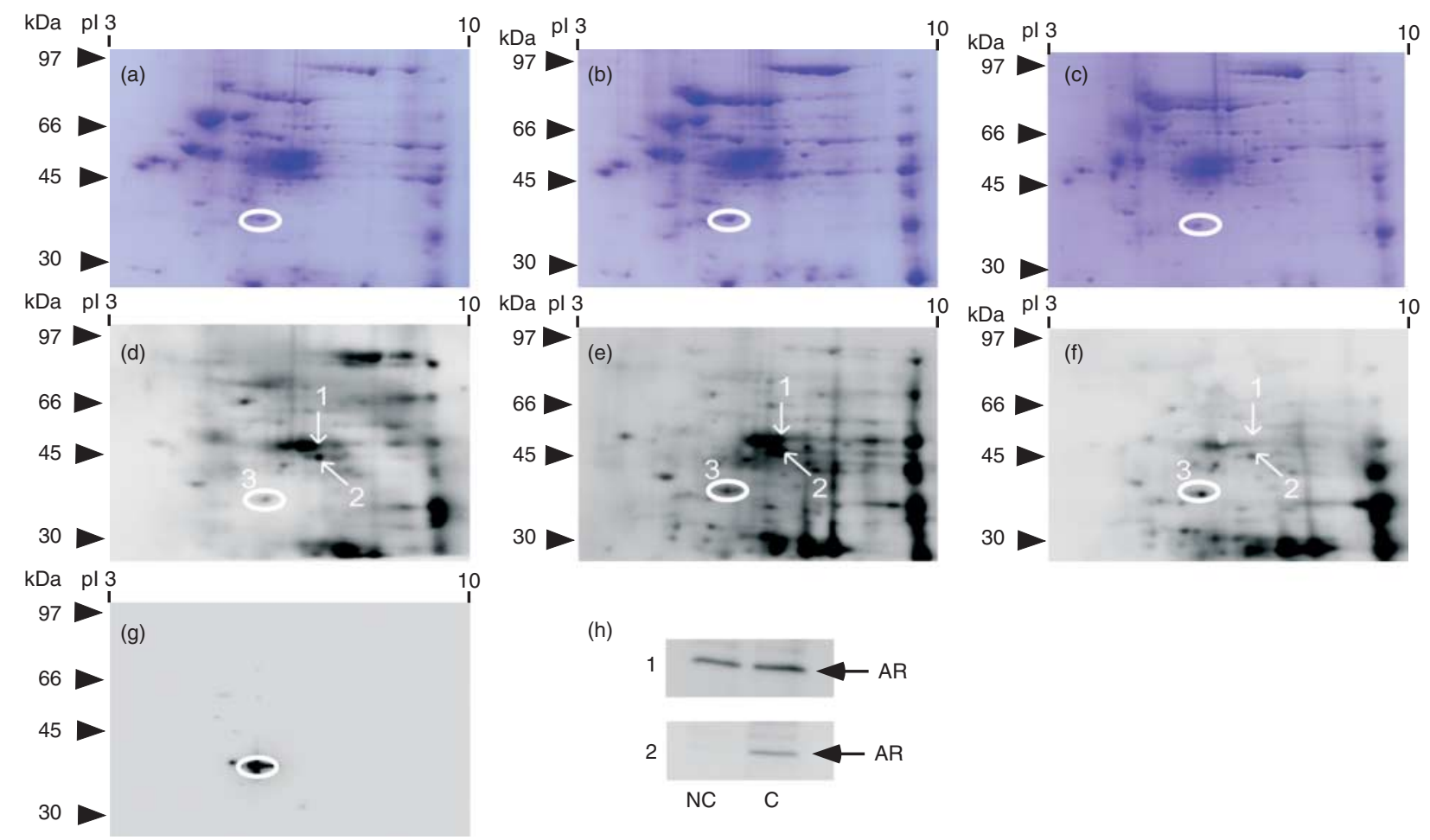

(h)

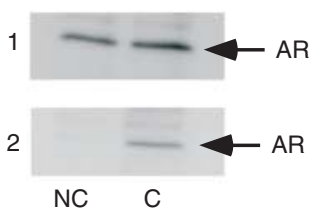

Figure 3 Identification of tyrosine phosphorylated proteins in the porcine cauda epididymal sperm. Total sperm proteins were extracted and separated by 2-DE (a, b, c, d, e, f and g). CBB staining and western blotting analyses either on tyrosine phosphorylated proteins in the noncapacitated sperm ( $\mathrm{a}$ and $\mathrm{d}$ ), in the capacitated sperm (b and e), or in the sperm capacitated in the presence of $500 \mu \mathrm{M}$ alrestatin (c and f) or on aldose reductase (g) in the noncapacitated sperm were carried out. The spots 1-3 were identified as the proteins phosphorylated during the incubation for capacitation. The circles indicate spots of aldose reductase. (h) Aldose reductase either in noncapacitated (NC) or capacitated (C) sperm was immunoprecipitated by anti-aldose reductase antisera as described in 'Materials and methods' section and then separated on a 12.5\% SDS-PAGE. Western blotting analyses on aldose reductase (1) or phosphotyrosine (2) were carried out.

homogenized with homogenizing buffer and separated into supernatant ('soluble fraction') and precipitate fractions by centrifugation at $105000 \mathrm{~g}$ for $90 \mathrm{~min}$ at $4{ }^{\circ} \mathrm{C}$. Proteins in the precipitate fraction were extracted with the same volume of $1 \%$ Triton X-100 in homogenizing buffer ('particulate fraction'). By the immunoprecipitation method, most of the aldose reductase was shown to be in the soluble fraction of porcine sperm (Fig. 5e1). From the ratio of the band intensity of the particulate fraction $(1435 \pm 161$ pixel) to that of the soluble fraction (10 709 \pm 402 pixel), determined using the freely available ImageJ Software (http://rsbweb.nih. gov/ij/teatures.html), about $12 \%$ of aldose reductase was determined to be associated with the particulate fraction.

Only the particulate-bound aldose reductase, not the soluble one, was detected as a tyrosine phosphoprotein (Fig. 5a , b, c and d). Furthermore, the extent of its tyrosine phosphorylation in the particulate fraction had significantly increased during capacitation. These results were also ascertained by the immunoprecipitation methods (Fig. 5e2).

\section{Changes in aldose reductase activity through capacitation}

Concomitantly with the increase in the tyrosine phosphorylation, the aldose reductase activity in the extract of the capacitated sperm was significantly higher than that in the noncapacitated sperm (Fig. 6). The aldose reductase activity in the particulate fraction was also markedly higher than that in the soluble fraction. Only the particulate-bound enzyme activity was proved to be enhanced by capacitation. Taking into account the content of aldose reductase calculated by the density

Table 1 Identification of proteins tyrosine phosphorylated during capacitation.

\begin{tabular}{llccrrr}
\hline Spot ID & Protein name & $\begin{array}{c}\text { Theoretical } \mathbf{M r}(\mathrm{kDa}) / \mathbf{p l} \\
\text { of } \text { matched protein }\end{array}$ & $\begin{array}{c}\text { Peptides } \\
\text { matched }\end{array}$ & $\begin{array}{c}\text { Mouse } \\
\text { score }\end{array}$ & $\begin{array}{c}\text { Sequence } \\
\text { coverage }\end{array}$ & $\begin{array}{c}\text { NCBI } \\
\text { accession no. }\end{array}$ \\
\hline 1 & B-enolase 3 & $47.1 / 8.05$ & 3 & 62 & 12 & $\mathrm{ABG73136.1}$ \\
2 & Isocitrate dehydrogenase 1 & $40.5 / 6.37$ & 5 & 58 & 24 & $\mathrm{ABD77226.1}$ \\
3 & Aldose reductase (AKR1B1) & $35.8 / 5.89$ & 6 & 118 & 42 & $\mathrm{AK3} 398724$ \\
\hline
\end{tabular}

The spot number listed in the table is in accordance with the spot number shown in Fig. 3. 
1 ggttggcetactggaggetatttaagggaccatactgccacctcggetgegtggtcctcc

61 ggtccgagtctgaggagctccgcagtcatggccagccacctcgtgetctacaccggtgec

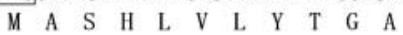
aagatgcccatcttggggctgggcacctggaagtccctccaggcaaagtgacagaggct $\begin{array}{lllllllllllllllllllll}\text { K } & \text { M } & \text { P } & \text { I } & \text { L } & G & \text { L } & G & \text { T } & \text { W } & \text { K } & \text { S } & \text { P } & \text { P } & G & \text { K } & \text { V } & \text { T } & \text { E } & \text { A }\end{array}$ gtgaaggtggccattgaccttgggtaccgccacattgactgtgcccatgtgtaccagaac $\begin{array}{lllllllllllllllllllll}\text { V } & \text { K } & \text { V } & \text { A } & \text { I } & \text { D } & \text { L } & \text { G } & \text { Y } & \text { R } & \text { H } & \text { I } & \text { D } & \text { C } & \text { A } & \text { H } & \text { V } & \text { Y } & \text { Q } & \text { N }\end{array}$ gagaacgaggtggggctgggcctccaggagaagctccaagggcaggtggtgaagcgtgag

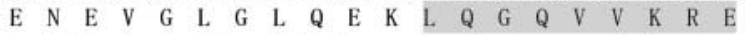
gacctcttcatcgtcagtaagctgtggtgcacagaccatgagaagaacctggtgaaaggg $\begin{array}{llllllllllllllllllll}\text { D } & \text { L } & \text { F } & \text { I } & \text { V } & \text { S } & \text { K } & \text { L } & \text { W } & \text { C } & \text { T } & \text { D } & \text { H } & \text { E } & \text { K } & \text { N } & \text { L } & \text { V } & \text { K } & \text { G }\end{array}$ gcctgccagacgaccetccgcaacctgaagctggactacctggacctctaccttatccac

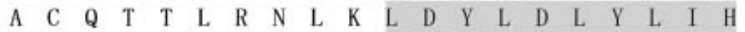
tggcccactggcttcaagcctggcaaggaccetttcccgctggatggcgacggcaacgtg W gttcctgatgagagcgattttgtggagacgtgggaggccatggaggagctggtggacgaa $\begin{array}{llllllllllllllllllll}V & \text { P } & D & E & \text { S } & \text { D } & \text { F } & \text { V } & \text { E } & \text { T } & \text { W } & \text { E } & \text { A } & \text { M } & \text { E } & \text { E } & \text { L } & \text { V } & \text { D } & \text { E }\end{array}$ gggctggtgaaagccattggcgtctccaacttcaaccatctgcaagtggagaagatctta

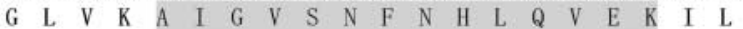
aacaaacctggcctgaaatacaagccagccgttaaccagatcgaggtccacccatacctc $\begin{array}{llllllllllllllllllll}N & K & P & G & \text { L } & K & \text { Y } & \text { K } & \text { P } & \text { A } & \text { V } & \text { N } & \text { Q } & \text { I } & \text { E } & \text { V } & \text { H } & \text { P } & \text { Y } & \text { L }\end{array}$ actcaggagaagttaatcgaatactgcaagtccaaaggcatcgtggtgactgcctacagc $\begin{array}{lllllllllllllllllllll}T & Q & E & K & \text { L } & \text { I } & \text { E } & \text { Y } & C & \text { K } & \text { S } & K & G & \text { I } & V & \text { V } & \text { T } & \text { A } & \text { Y } & \text { S }\end{array}$ cccctcggetctcccgacaggccetgggccaagcctgaggaccttccetcctggaggac $\begin{array}{llllllllllllllllllll}\text { P } & \text { L } & G & \text { S } & \text { P } & \text { D } & R & \text { P } & \text { W } & \text { A } & \text { K } & \text { P } & \text { E } & \text { D } & \text { P } & \text { S } & \text { L } & \text { L } & \text { E } & \text { D }\end{array}$ cccaggatcaaagcgattgcagccaagtacaataaaaccacagcccaggttctgatccgg $\begin{array}{llllllllllllllllllll}\text { P } & R & \text { I } & \text { K } & \text { A } & \text { I } & \text { A } & \text { A } & \text { K } & \text { Y } & \text { N } & \text { K } & \text { T } & \text { T } & \text { A } & \text { Q } & \text { V } & \text { L } & \text { I } & R\end{array}$ ttcccatgcagaggaacttgatcgtcatccccaagtccgtgacgcctgaacgcattgcc

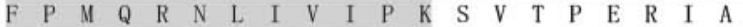
gagaacttccaggtctttgactttgaactgagccctgaggatatgaacaccttactgagc $\begin{array}{lllllllllllllllllllll}\text { E } & N & \text { F } & \text { Q } & \text { V } & \text { F } & \text { D } & \text { F } & \text { E } & \text { L } & \text { S } & \text { P } & \text { E } & \text { D } & \text { M } & \text { N } & \text { T } & \text { L } & \text { L } & \text { S }\end{array}$ tacaacaggaactggagggtctgtgccttgatgagctgtgcetcccacaaggattatccc $\begin{array}{lllllllllllllllllllll}\text { Y } & \text { N } & \text { R } & \text { N } & \text { W } & \text { R } & \text { V } & \text { C } & \text { A } & \text { L } & \text { M } & \text { S } & \text { C } & \text { A } & \text { S } & \text { H } & \text { K } & \text { D } & \text { Y } & \text { P }\end{array}$

ttcacgaggaatat tgaagctgggggtgectgccttcccaggtgacctgetgtttec F

1081 ctcctcgettccccctgccagtggagctcggccctgtccetcggcagcgggtcagcg 1141 acccaccgaggegccagtgggegettggectgcatggtgtggggccegaagagcactacc 1201 tgtagattggaagtccetccagtttcttcgcccegcttcttgtccagctgcggacagcg 1261 cgccgtgaataccettttctaagttgaatttcaaagtgaaaacagcacctctaacagtt 1321 ggatttgactgcttggaactgtgctcctttcagctagacttttccttgcctcaaataaa 1381 aagtgctcttatgaatttgcaaaaaaaaaaaaaaaaaaaaaaaaaaaaaaaaaa

Figure 4 Nucleotide and deduced amino acid sequences of aldose reductase (accession no. AK398724). The regions used for the preparation of the recombinant protein are indicated by underline. Six peptides identified by the mass spectrometry are indicated by shaded boxes. The stop codon "tga" is indicated by open box with asterisk (*).

of its spot in the western blotting analysis (Fig. 5e1), the approximate ratio of the specific activity of aldose reductase in the soluble fraction to that in the particulate fraction prepared from the capacitated sperm was estimated to be 1:45.

\section{Effects of alrestatin on induction of hyperactivation and capacitation and on the levels of tyrosine phosphorylation and ROS in sperm}

To reveal whether aldose reductase activity is involved in the capacitation of porcine cauda epididymal sperm, we investigated the effects of alrestatin, a membranepermeable and specific inhibitor of aldose reductase, on induction of hyperactivation and capacitation of sperm. Capacitation was markedly inhibited in the presence of
$500 \mu \mathrm{M}$ alrestatin (Fig. 2). Interestingly, alrestatin also significantly inhibited the decrease in the concentrations of GSH in sperm during capacitation (Fig. 7).

Furthermore, the tracks of sperm movement had clearly changed from progressive movement pattern to circular, figure-of-eight, and star-spin movement patterns as a result of their incubation with Cap medium (Figs 1a and 8a). These changes in sperm motility were analyzed by CASA. The changes in the motion parameters induced by capacitation were the characteristic of hyperactivated sperm, i.e. increases in VCL, VSL, VAP, and ALH as well as decreases in LIN and STR (Schmidt \& Kamp 2004, Matás et al. 2010; Table 2). These changes were also inhibited by alrestatin.

Alrestatin inhibited both hyperactivation and aldose reductase activity to the same extent and at the same concentrations (Fig. 8c and d). The alrestatin-induced inhibition of hyperactivation was positively correlated with the aldose reductase activity $(n=6 ; r=0.976$;
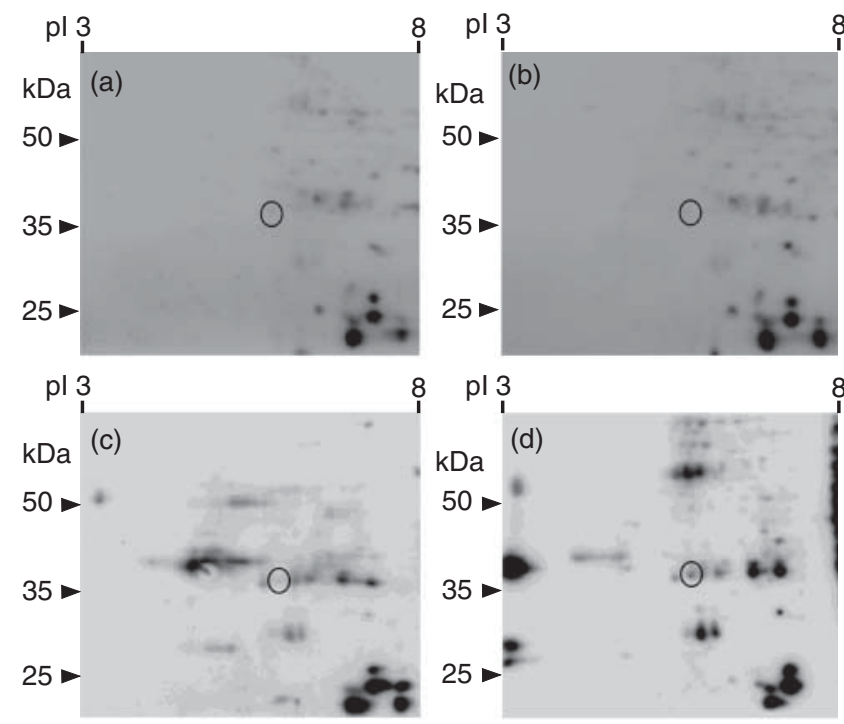

(e)

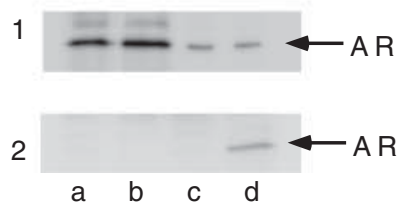

Figure 5 Tyrosine phosphorylation of aldose reductase in particulate fraction of sperm during capacitation. Both soluble fraction ( $a$ and $b$ ) and particulate fraction (c and d) were prepared from $2.5 \times 10^{7}$ of noncapacitated ( $a$ and $c$ ) or capacitated (b and d) sperm as described in 'Materials and methods' section. Then, $119 \mu$ l of each sample was applied to western blotting analyses on tyrosine phosphoproteins. The circles indicate aldose reductase. (e) The distribution of aldose reductase in soluble and particulate fraction was determined by immunoprecipitation method. Aldose reductase in $500 \mu \mathrm{l}$ of the same protein fractions used in ( $\mathrm{a}, \mathrm{b}, \mathrm{c}$ and $\mathrm{d})$ was immunoprecipitated and separated on a $12.5 \%$ SDS-PAGE and western blotting analyses on aldose reductase (1) or tyrosine phosphoproteins (2) were carried out. 


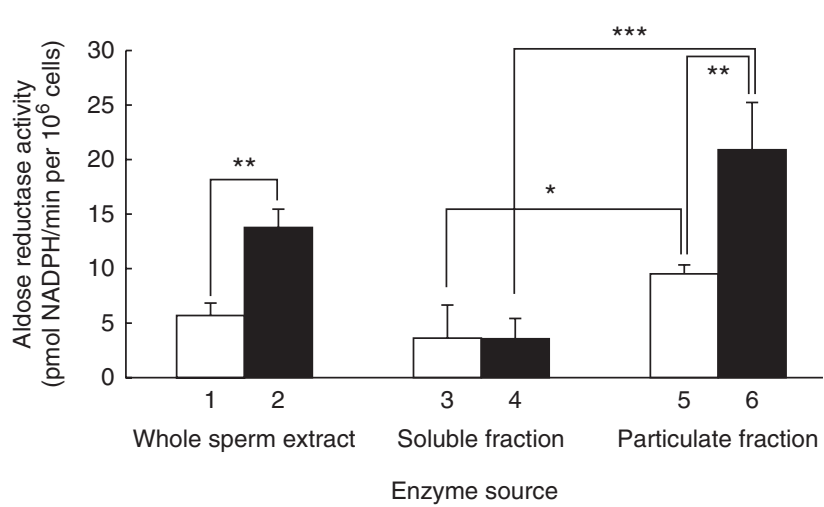

Figure 6 Changes in the sperm aldose reductase activities through capacitation. The aldose reductase activities of whole sperm extract, soluble fraction, and particulate fraction prepared from the noncapacitated (open bar) or capacitated (closed bar) sperm were determined as described in 'Materials and methods' section. Data are expressed as mean \pm S.E.M. from six determinations. ${ }^{*} P<0.05$, ${ }^{* *} P<0.01$, and ${ }^{* * *} P<0.001$.

$P<0.001$ ). The concentrations of alrestatin that induced half-maximal inhibition of hyperactivation and aldose reductase were 53 and $45 \mu \mathrm{M}$ respectively. On the other hand, CP-470,711, a membrane-permeable and specific inhibitor of SORD (the second enzyme of the polyol pathway), did not show any significant effects on capacitation (data not shown).

The intensity of $\mathrm{H}_{2}$ DCFDA fluorescence in sperm was enhanced during capacitation, but was largely reduced in the presence of alrestatin (Fig. 8b). The alrestatin-induced inhibition of the ROS production also showed a significantly positive correlation with that of the aldose reductase activity ( $n=6 ; r=0.945 ; P<0.01$; Fig. 8 c and d).

Taken together, these findings show that capacitation is associated with increases in both ROS production and protein tyrosine phosphorylation in sperm. Alrestatin was found to inhibit both. The overall increase in tyrosine phosphorylation was observed in the proteins extracted from the capacitated sperm. It was found that protein tyrosine phosphorylation did not increase in sperm capacitated in the presence of alrestatin, and alrestatin significantly decreased the tyrosine phosphorylation of aldose reductase (Fig. 2f).

\section{Effects of extracellular monosaccharides on sperm motility}

Monosaccharide content in the fluid surrounding sperm changes during transit through the genital tracts from the ductus epididymidis to the oviduct (Pruneda et al. 2006). Namely, in the epididymal fluid, fructose is the predominant monosaccharide, and its content in the seminal plasma is further increased by the secretions from the seminal vesicles at ejaculation. On the other hand, glucose is a major monosaccharide in the oviduct fluids, where sperm undergo capacitation. Porcine sperm are known to be quiescent in the cauda epididymis and to initiate forward movement at ejaculation. The extent of induction of forward motility of the cauda epididymal sperm by bicarbonate was the same in the presence of glucose as that in the presence of fructose (Fig. 9a). Alrestatin reduced the initiation of forward motility in the presence of glucose, but not in the presence of fructose.

Hyperactivated movement of the cauda epididymal sperm was markedly induced by incubation in Cap medium containing glucose, which was almost completely inhibited by alrestatin (Fig. 9b). The replacement of glucose with fructose decreased the number of hyperactivated sperm, which were resistant to alrestatin inhibition.

\section{Acquisition of aldose reductase by sperm during maturation in the epididymis}

Immunohistochemical analyses showed that in the seminiferous tubules, aldose reductase is localized in the Sertoli cells, but not in the germ cells (Fig. 10a). It has been suggested that aldose reductase is incorporated into sperm from the epididymal fluid via epididymosomes while sperm pass through the epididymis (Caballero et al. 2011). In our experiments, aldose reductase mRNA was expressed to similar extents in the testis and the caput and corpus epididymidis and to a lower extent in the cauda epididymis (Fig. 10b). The concentrations of aldose reductase in the luminal fluids were greatly increased from the testis to the caput epididymis and diminished in the cauda epididymidis (Fig. 10c and d). Testicular sperm contained lower levels of aldose reductase than did caput epididymal sperm. The content of aldose reductase in sperm gradually increased during their transit through the epididymis (Fig. 10e and f).

\section{Discussion}

This is the first report on phosphorylation of aldose reductase at a tyrosine residue. We also found that both

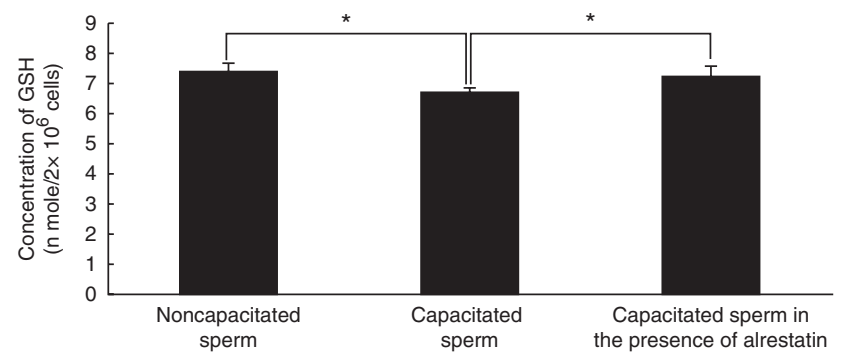

Figure 7 Effect of alrestatin on the concentrations of GSH. The GSH levels were determined on sperm incubated either in Non-cap medium or in Cap medium in the absence or the presence of $500 \mu \mathrm{M}$ alrestatin. The concentrations of GSH were determined as described in 'Materials and methods' section. Data are expressed as mean \pm S.E.M. from six determinations. ${ }^{*} P<0.05$. 
tyrosine phosphorylation and enzymatic activity of aldose reductase were enhanced during capacitation. In this study, most of the aldose reductase in porcine sperm was shown to be present in the soluble fraction,

(a)

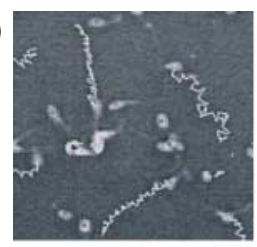

(b)

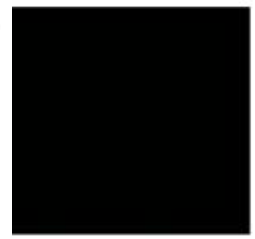

Noncapacitated sperm

(c)

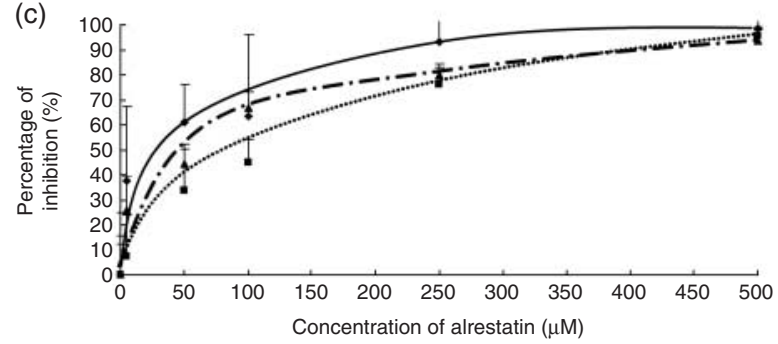

(d)

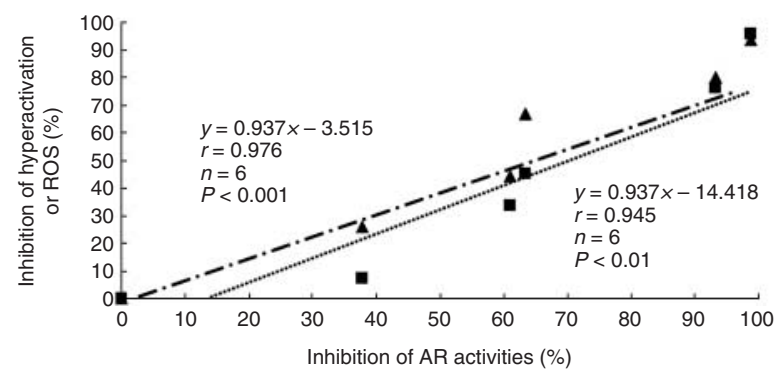

Figure 8 Effects of alrestatin on the changes in the motility, ROS levels, and aldose reductase activities of porcine sperm during capacitation. Cauda epididymal sperm were incubated in Non-cap or Cap medium in the presence or the absence of $500 \mu \mathrm{M}$ alrestatin at $37^{\circ} \mathrm{C}$ for $3 \mathrm{~h}$ under $5 \% \mathrm{CO}_{2}$. (a) Changes in the movement of the cauda epididymal sperm were observed under the microscope. Swimming trajectories were obtained with CASA (frame rate $60 \mathrm{~Hz}$, frame acquired 55). (b) ROS contents in sperm were analyzed using $\mathrm{H}_{2}$ DCFDA as a probe and observed under the microscope. Bar $=100 \mu \mathrm{m}$. (c) Effects of the concentration of alrestatin on aldose reductase activities (rhombus, solid line), hyperactivation of motility (triangle, chain line), and production of ROS (square, dotted line). Aldose reductase activity of whole sperm extract, percentage of hyperactivated sperm in motile sperm, and ROS levels were determined in the sperm capacitated in the presence of various concentrations of alrestatin. Data are expressed as percentage of alrestatin induced inhibition and shown by mean \pm S.E.M. from four determinations. (d) The correlations between the inhibition of aldose reductase activity and the inhibition of hyperactivation (triangle, chain line) or ROS production (square, dotted line) by alrestatin. The data obtained in (c) were replotted. and the rest, about $12 \%$ of the total aldose reductase, was found in the particulate fraction. Only particulatebound fraction of aldose reductase, not in the soluble fraction, was shown to be tyrosine phosphorylated. Furthermore, tyrosine phosphorylation of aldose reductase in the particulate fraction significantly increased during capacitation.

The activity of aldose reductase in the soluble fraction was found to be lower than that in the particulate fraction and unchanged throughout capacitation. On the other hand, aldose reductase activity in the particulate fraction was significantly increased through capacitation. These results suggest that the activity of aldose reductase is stimulated by its tyrosine phosphorylation. Although the significant changes in the distribution of aldose reductase between the soluble and the particulate fraction were not detected during capacitation under the present conditions, it is likely that translocation of aldose reductase from the cytosol to the particulate fraction occurs concomitantly with the increases in its tyrosine phosphorylation and enzymatic activity during capacitation. In this connection, a very interesting report showed that stimulation of protein kinase $C$ in several cell types induces phosphorylation of aldose reductase and its mitochondrial translocation (Varma et al. 2003). Although it has been suggested that the SRC family and receptor-activated tyrosine kinases are involved in capacitation, the enzyme that tyrosine phosphorylates aldose reductase must be identified (de Lamirande \& Gagnon 2002, O'Flaherty et al. 2005, 2006a,b, Baker et al. 2009).

Mammalian sperm first acquire the capacity for motility and fertility during transit through the epididymis, a process called 'epididymal maturation'. But the sperm must be activated at least twice more to exert those capacities. The constituents surrounding sperm are very important for attaining these activation processes (Boatman 1997, Satake et al. 2006). The first activation occurs at ejaculation. In porcine sperm, the concentration of extracellular bicarbonate increases from about $2 \mathrm{mM}$ in the cauda epididymal fluid to over $20 \mathrm{mM}$ in semen, which activates bicarbonate-sensitive, soluble adenylyl cyclase, resulting in the stimulation of $\mathrm{O}_{2}$ consumption and in the initiation of coordinated forward movement of sperm (Tajima et al. 1987). The concentration of bicarbonate further increases to above $30 \mathrm{mM}$ in the oviduct fluids, where sperm acquire fertilizing capacity through the second activation process, namely 'capacitation' (Maas et al. 1977, Rodríguez-Martínez et al. 2005). In addition, although fructose is the predominant respiratory substrate for sperm in semen, it is then replaced by glucose in the oviduct fluids (Mann 1946, Hugentobler et al. 2008, Larose et al. 2012). GLUT1 has been shown to play an important role in glucose transfer from the oviduct epithelium into the lumen and in the maintenance of adequate glucose concentrations in the oviduct fluid (Tadokoro et al. 
Table 2 Motility parameters measured by CASA for capacitated and noncapacitated sperm.

\begin{tabular}{lccccccc}
\hline Treatment & VCL $(\mu \mathrm{m} / \mathrm{s})$ & VSL $(\mu \mathrm{m} / \mathrm{s})$ & VAP $(\mu \mathrm{m} / \mathrm{s})$ & LIN $(\%)$ & STR $(\%)$ & ALH $(\mu \mathrm{m})$ & BCF $(\mathrm{Hz})$ \\
\hline Non-cap & $67.03 \pm 24.62$ & $26.60 \pm 3.97$ & $35.47 \pm 4.70$ & $46.33 \pm 3.51$ & $73.33 \pm 3.06$ & $3.90 \pm 0.66$ \\
Cap & $144.37 \pm 20.11^{*}$ & $47.43 \pm 8.00^{*}$ & $73.37 \pm 14.16^{*}$ & $33.67 \pm 2.52^{*}$ & $60.33 \pm 1.53^{*}$ & $5.97 \pm 1.00^{* *}$ & $32.13 \pm 1.88$ \\
Cap+alrestatin & $83.13 \pm 16.57$ & $27.53 \pm 5.11$ & $40.93 \pm 4.58$ & $48.00 \pm 4.36$ & $69.67 \pm 2.52$ & $3.87 \pm 0.32$ & $27.67 \pm 5.13$ \\
$P$ value & $<0.01$ & $<0.01$ & $<0.01$ & $<0.01$ & $<0.01$ & $<0.05$ & $>0.05$ \\
\hline
\end{tabular}

VCL, curvilinear velocity; VSL, straight-line velocity; VAP, average path velocity; LIN, linearity of the curvilinear trajectory $(\mathrm{VSL} \times 100 / \mathrm{VCL})$; STR, straightness (VSLX100/VAP); ALH, amplitude of lateral head displacement; BCF, beat cross-frequency.

${ }^{*} P<0.01 ;{ }^{*} P<0.05$.

1995). The concentrations of glucose in the oviduct fluid, which differ substantially among mammals, have been shown to increase during the preovulatory period of the estrous cycle (Vecchio et al. 2010). In pigs, Nichol et al. (1992) reported that the concentrations of glucose were significantly lower in the whole oviduct $(0.59 \mathrm{mM})$ than in the blood plasma $(4.56 \mathrm{mM})$, but its concentration in the ampullary-isthmic junction during the preovulatory period $(1.65 \mathrm{mM})$ was greater than during other periods of the estrous cycle. In boar sperm, the utilization of glucose is controlled in part by the heterogeneous localization of GLUT family transporters over the entire sperm surface (Bucci et al. 2010).

Sperm aldose reductase seems to be physiologically quiescent until sperm arrive in the cauda epididymis because the concentrations of the extracellular respiration substrates, glucose and fructose, are extremely low (Pruneda et al. 2006). It has been reported that unactivated aldose reductase of human erythrocytes exhibits biphasic kinetics with $\mathrm{Km}$ of glucose $=9.0$ and $0.9 \mathrm{mM}$, whereas the activated form exhibits monophasic kinetics with $\mathrm{Km}$ of glucose $=0.68 \mathrm{mM}$ (Srivastava et al. 1985), which is lower than the glucose concentration in the ampullary-isthmic junction during the preovulatory period. Therefore, aldose reductase activated through tyrosine phosphorylation is strongly suggested to function physiologically during capacitation in the oviduct. Furthermore, glucose metabolism can be activated by high concentrations of bicarbonate through activation of bicarbonate-sensitive, soluble adenylyl cyclase, resulting in increase in glyceraldehyde 3-phosphate, which is a physiologically relevant substrate with high affinity for aldose reductase $(\mathrm{Km}=$ $0.66 \mu \mathrm{M}$; (Giacco \& Brownlee 2010)).

During capacitation, mammalian sperm change their motility pattern from progressive movement to hyperactivated one characterized by asymmetrical, highamplitude flagellar beats (Yanagimachi 1994, Suarez \& Ho 2003). When porcine cauda epididymal sperm were incubated in Non-cap medium containing bicarbonate, the sperm initiated forward movement but did not show a hyperactivated movement. The extent of forward motility of the cauda epididymal sperm in the presence of glucose was similar to that in the presence of fructose. Alrestatin partially inhibited the forward motility only in the presence of glucose. In this connection, Cheng \& (a)
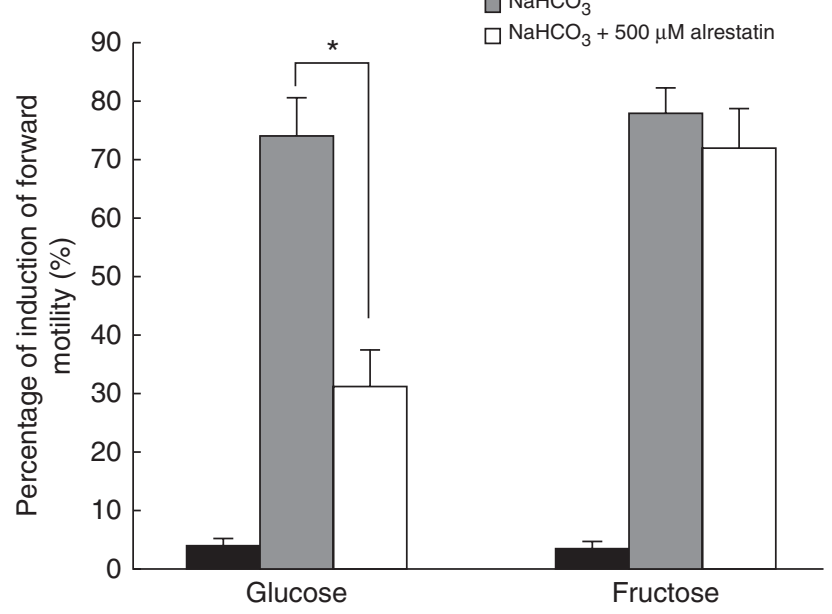

(b)

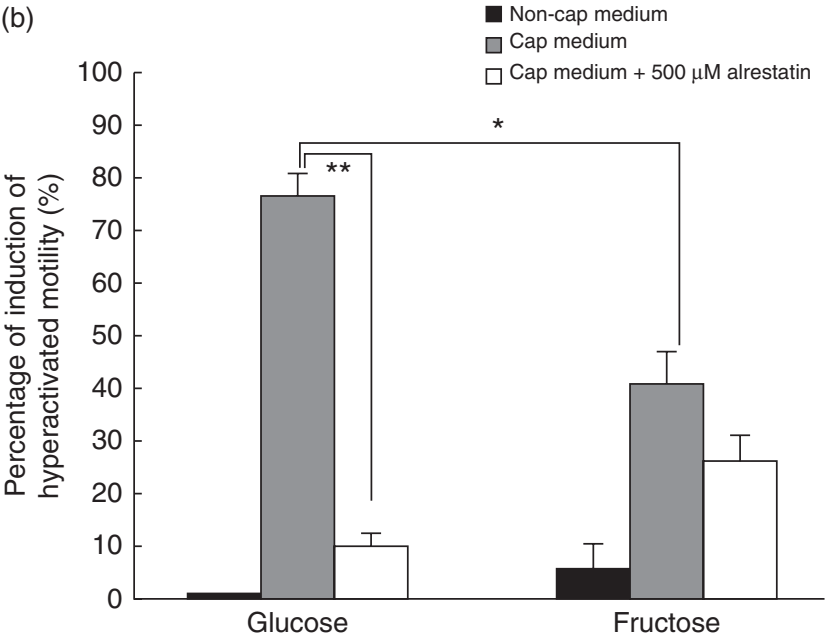

Figure 9 Effects of glucose and fructose on the sperm motility. (a) Effects of alrestatin on the initiation of the forward motility by bicarbonate in the presence of either glucose or fructose. The forward motility of cauda epididymal sperm was induced by the addition of $20 \mathrm{mM} \mathrm{NaHCO}_{3}$ in Non-cap medium at $37^{\circ} \mathrm{C}$. (b) Effects of alrestatin on the induction of hyperactivation in the presence of either glucose or fructose. Cauda epididymal sperm were incubated in Non-cap or Cap medium containing either glucose or fructose in the presence or absence of $500 \mu \mathrm{M}$ alrestatin. The percentage of sperm showing forward motility (a) or hyperactivated motility (b) to motile sperm was calculated under the microscope. Data are expressed as mean \pm s.E.M. from triplicate determinations. ${ }^{*} P<0.01$ and ${ }^{* *} P<0.001$. 
(a)

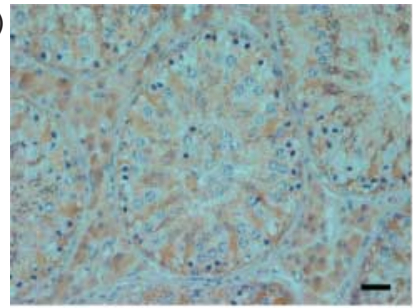

(b)

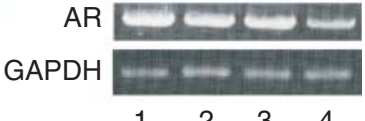

(c)

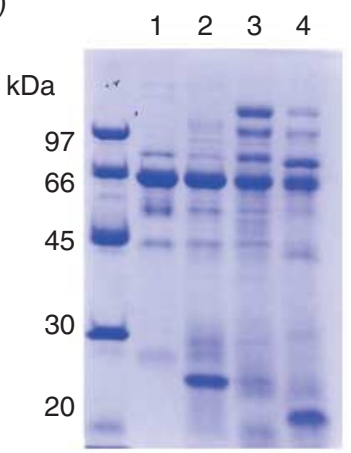

(e)

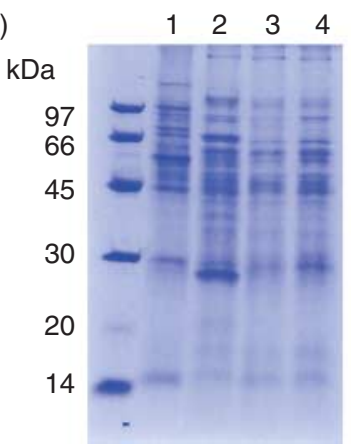

(d)
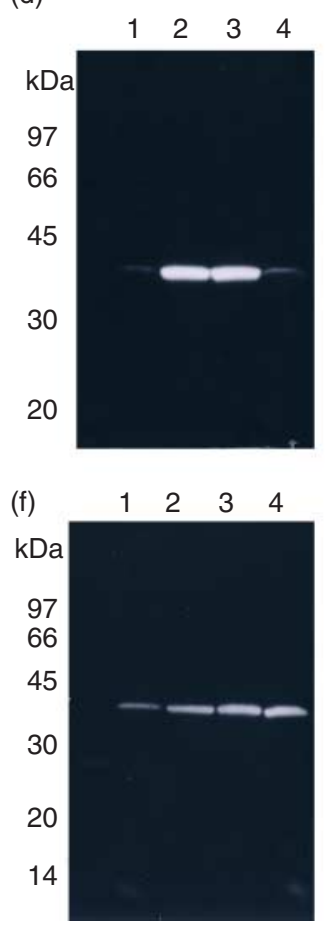

Figure 10 Expression of aldose reductase in testis and epididymis. (a) Immunohistochemical localization of aldose reductase in the porcine testis was analyzed with anti-aldose reductase antisera. Bar $=50 \mu \mathrm{m}$. (b) Expression of aldose reductase mRNA. Expression of aldose reductase $\mathrm{mRNA}$ in testis and various regions of epididymis was analysed by RT-PCR. GAPDH was used as a loading control. (c, d, e and f) Localization of aldose reductase proteins in the luminal fluids ( $c$ and d) and sperm (e and f) prepared from testis and various regions of epididymis. $15 \mu \mathrm{g}$ proteins of the luminal fluids and sperm extract were separated on a $10 \%$ SDS-PAGE and then stained with CBB (c and e) or analysed by western blotting analyses with anti-aldose reductase antisera ( $d$ and f). (1) Testis, (2) caput epididymis, (3) corpus epididymis, and (4) cauda epididymis.

González (1986) have reported that under hyperglycemic conditions, about $30 \%$ of glucose enters the polyol pathway. In this study, however, sperm incubated in Cap medium for $3 \mathrm{~h}$ exhibited hyperactivated motility. As capacitation was induced at $37^{\circ} \mathrm{C}$ rather than $39{ }^{\circ} \mathrm{C}$ in order to maintain higher viability and motility of porcine cauda epididymal sperm during the incubation for capacitation and $\mathrm{Ca}^{2+}$ ionophore was not contained in Cap medium, it is possible that full induction of hyperactivation has not been achieved under the present condition. But swimming patterns and flagellar

movements shown in Fig. $1 \mathrm{~b}$ as well as CASA parameters in Table 2 all satisfied the properties and threshold values of the hyperactivation of porcine sperm. Alrestatin was shown to largely inhibit hyperactivated motility. When the glucose in Cap medium was replaced by fructose, the extent of hyperactivated sperm was largely reduced and not inhibited by alrestatin. These results suggest that induction of hyperactivated motility in vitro is dependent on aldose reductase activity. Although it has been proposed that capacitation and hyperactivation are regulated by different signal pathways (Marquez \& Suarez 2004), aldose reductase is suggested to concern in both events.

It has been well accepted that under the hyperglycemic condition, the polyol pathway is activated to induce intracellular oxidative stress and that aldose reductase is the major contributor to diabetes-induced oxidative stress in the lens, kidney, and nerve (Kinoshita \& Nishimura 1988). On the other hand, aldose reductase has been reported to protect cells from high osmotic pressure to accumulate sorbitol within the cells (Burg 1995). In the female reproductive system of the rat, aldose reductase has been suggested to function as a detoxification agent against toxic carbonyl compounds (Kaneko et al. 2003), but the physiological function of aldose reductase in sperm remains unclear (Kobayashi et al. 2002).

Before capacitation, as aldose reductase activity is low, most of the cellular glucose is converted to glucose 6-phosphate, which is then processed to glycolysis. Some parts of glucose are converted to sorbitol by increased activities of aldose reductase during capacitation, consuming NADPH (Fernández-Novell et al. 2004, Medrano et al. 2006). We found that alrestatin inhibited the production of ROS, tyrosine phosphorylation of proteins, and induction of hyperactivation as assessed by CASA, which were all observed during the course of capacitation, at the same concentration range as that at which alrestatin induced inhibition of aldose reductase activity. We also found that alrestatin diminished the decrease in GSH in sperm as well as the induction of pattern B of CTC fluorescence staining that occurred during capacitation. These results suggest that the consumption of NADPH induced by increased aldose reductase activity decreased the activity of GSH reductase, which also requires $\mathrm{NADPH}$ as a cofactor, resulting in the decrease in GSH and the antioxidant capacity of sperm. Namely, this increased aldose reductase activity is one of the sources of ROS production in sperm during capacitation. Previous studies have shown that ROS at a physiological concentration induce capacitation through increasing protein tyrosine phosphorylation (de Lamirande et al. 1997, Roy \& Atreja 2008). NADPH is mainly generated by pentose phosphate pathway and has reported to play important roles in the processes of sperm-egg fusion (Aitken et al. 1995). Activities of glucose 6-phosphate dehydrogenase, the first enzyme of pentose phosphate 
pathway which functions to generate $\mathrm{NADPH}$, have been reported in sperm of human (Peterson \& Freund 1970) and mouse (Ferrandi et al. 1995), but not in bull (Hammerstedt 1975) and boar (Marin et al. 2003). Therefore, in boar sperm both malic enzyme and cytosolic NADP-dependent isocitrate dehydrogenase (isocitrate dehydrogenase 1) may be responsible to produce NADPH. It is very interesting that we also identified isocitrate dehydrogenase 1 as one of the proteins tyrosine phosphorylated during capacitation (Fig. 2 and Table 1). The study on the roles of isocitrate dehydrogenase 1 in the porcine sperm capacitation is in progress now.

Recently, it has been reported that the activity of sperm SORD, the second enzyme of the polyol pathway, is also increased during capacitation (Baker et al. 2010) and that sorbitol can also serve as an energy source for sperm motility and protein tyrosine phosphorylation via SORD (Cao et al. 2009). However, under the present experimental conditions, the SORD inhibitor, CP-470,711, did not show any significant effects on the induction of hyperactivated motility. Although our results suggest that aldose reductase is involved in capacitation not by supplying energy sources but by producing low levels of ROS, both enzymes in the polyol pathway might not be indispensable for sperm to fertilize oocytes, because it has been reported that neither aldose reductase- nor SORD-deficient mice demonstrate any apparent reproductive abnormality (Holmes et al. 1982, Ho et al. 2000). These results suggest that other pathways compensate the deletion of aldose reductase by regulating physiological ROS levels of sperm in mice.

A previous study suggested that epididymosomes support in sperm acquisition of motile and fertile capacities by the addition of epididymal proteins to maturating sperm (Caballero et al. 2011). Aldose reductase as well as SORD has been reported to be one of the constituents of epididymosomes (Frenette et al. 2004, Sullivan et al. 2005). Consistent with these previous findings, in this study, the levels of aldose reductase in the fluids of the caput and corpus epididymidis were shown to be extremely higher than in those of the testis. And testicular sperm were found to contain very low aldose reductase and to acquire it during passage through the epididymis. In this connection, an interesting report showed that the expression of aldose reductase in the oviduct is restricted to the isthmus, where sperm accomplish capacitation (Larose et al. 2012). Furthermore, other studies reported that the oviduct releases granules into the lumen, although the presence of aldose reductase in the granules remains to be proven (Nayak \& Ellington 1977, Eriksen et al. 1994). These results suggest that acquisition of aldose reductase by sperm is involved in the posttesticular functional maturation of sperm. In other words, aldose reductase may be one of the important factors that confer fertilizing capacity on sperm during their functional maturation.

\section{Supplementary data}

This is linked to the online version of the paper at http://dx.doi. org/10.1530/REP-14-0199.

\section{Declaration of interest}

The authors declare that there is no conflict of interest that could be perceived as prejudicing the impartiality of the research reported.

\section{Funding}

This work was supported by the Ministry of Education, Culture, Sports, Science, and Technology in Japan.

\section{Acknowledgements}

The authors deeply express their gratefulness to Dr T Nagai, Ms M Arimoto, and Ms E Satoh for their valuable suggestions and encouragement. They would like to thanks Dr Flaminia Miyamasu of the Medical English Communications Center of the University of Tsukuba for proofreading the manuscript.

\section{References}

Aitken RJ \& Nixon B 2013 Sperm capacitation: a distant landscape glimpsed but unexplored. Molecular Human Reproduction 19 785-793. (doi:10.1093/molehr/gat067)

Aitken RJ, Paterson M, Fisher H, Buckingham DW \& van Duin M 1995 Redox regulation of tyrosine phosphorylation in human spermatozoa and its role in the control of human sperm function. Journal of Cell Science 108 2017-2025.

Awda BJ, Mackenzie-Bell M \& Buhr MM 2009 Reactive oxygen species and boar sperm function. Biology of Reproduction 81 553-561. (doi:10. 1095/biolreprod.109.076471)

Baker MA, Hetherington L, Curry B \& Aitken RJ 2009 Phosphorylation and consequent stimulation of the tyrosine kinase c-Abl by PKA in mouse spermatozoa; its implications during capacitation. Developmental Biology 333 57-66. (doi:10.1016/j.ydbio.2009.06.022)

Baker MA, Reeves G, Hetherington L \& Aitken RJ 2010 Analysis of proteomic changes associated with sperm capacitation through the combined use of IPG-strip pre-fractionation followed by RP chromatography LC-MS/MS analysis. Proteomics 10 482-495. (doi:10.1002/pmic. 200900574)

Bedard K \& Krause KH 2007 The NOX family of ROS-generating NADPH oxidases: physiology and pathophysiology. Physiological Reviews 87 245-313. (doi:10.1152/physrev.00044.2005)

Boatman DE 1997 Responses of gametes to the oviductal environment. Human Reproduction 12 133-149.

Bucci D, Isani G, Spinaci M, Tamanini C, Mari G, Zambelli D \& Galeati G 2010 Comparative immunolocalization of GLUTs 1, 2, 3 and 5 in boar, stallion and dog spermatozoa. Reproduction in Domestic Animals 45 315-322. (doi:10.1111/j.1439-0531.2008.01307.x)

Burg MB 1995 Molecular basis of osmotic regulation. American Journal of Physiology 268 F983-F996.

Caballero J, Frenette G \& Sullivan R 2011 Post testicular sperm maturational changes in the bull: important role of the epididymosomes and prostasomes. Veterinary Medicine International 2010757194. (doi:10.4061/2011/757194)

Cao W, Aghajanian HK, Haig-Ladewig LA \& Gerton GL 2009 Sorbitol can fuel mouse sperm motility and protein tyrosine phosphorylation via sorbitol dehydrogenase. Biology of Reproduction 80 124-133. (doi:10.1095/biolreprod.108.068882) 
Carter WO, Narayanan PK \& Robinson JP 1994 Intracellular hydrogen peroxide and superoxide anion detection in endothelial cells. Journal of Leukocyte Biology 55 253-258.

Cheng HM \& González RG 1986 The effect of high glucose and oxidative stress on lens metabolism, aldose reductase, and senile cataractogenesis. Metabolism 35 10-14. (doi:10.1016/0026-0495(86)90180-0)

Chung SS, Ho EC, Lam KS \& Chung SK 2003 Contribution of polyol pathway to diabetes-induced oxidative stress. Journal of the American Society of Nephrology 14 S233-S236. (doi:10.1097/01.ASN.0000077408. 15865.06)

Dacheux JL, Dacheux F \& Paquignon M 1989 Changes in sperm surface membrane and luminal protein fluid content during epididymal transit in the boar. Biology of Reproduction 40 635-651. (doi:10.1095/ biolreprod40.3.635)

Eriksen T, Terkelsen O, Hyttel P \& Greve T 1994 Ultrastructural features of secretory cells in the bovine oviduct epithelium. Anatomy and Embryology 190 583-590. (doi:10.1007/BF00190108)

Fernández-Novell JM, Ballester J, Medrano A, Otaegui PJ, Rigau T, Guinovart J \& Rodríguez-Gil JE 2004 The presence of a high-Km hexokinase activity in dog, but not in boar, sperm. FEBS Letters $\mathbf{5 7 0}$ 211-216. (doi:10.1016/j.febslet.2004.06.015)

Ferrandi B, Lange Consiglio A, Carnevali A \& Porcelli F 1995 Spontaneous lipid peroxidation and sperm metabolism during incubation in media simulating the oviductal microenvironment. Cellular and Molecular Biology 41 327-333.

Fraser LR 2010 The "switching on" of mammalian spermatozoa: molecular events involved in promotion and regulation of capacitation. Molecular Reproduction and Development 77 197-208.

Frenette G, Lessard C \& Sullivan R 2004 Polyol pathway along the bovine epididymis. Molecular Reproduction and Development 69 448-456. (doi:10.1002/mrd.20170)

Gadella BM \& Harrison RA 2000 The capacitating agent bicarbonate induces protein kinase A-dependent changes in phospholipid transbilayer behavior in the sperm plasma membrane. Development 127 2407-2420.

Giacco F \& Brownlee M 2010 Oxidative stress and diabetic complications. Circulation Research 107 1058-1070. (doi:10.1161/CIRCRESAHA.110. 223545)

Hammerstedt RH 1975 Tritium release from [2-3H]D-glucose as a monitor of glucose consumption by bovine sperm. Biology of Reproduction 12 545-551. (doi:10.1095/biolreprod12.5.545)

Harrison RA \& Gadella BM 2005 Bicarbonate-induced membrane processing in sperm capacitation. Theriogenology 63 342-351. (doi:10. 1016/j.theriogenology.2004.09.016)

Ho HT, Chung SK, Law JW, Ko BC, Tam SC, Brooks HL, Knepper MA \& Chung SS 2000 Aldose reductase-deficient mice develop nephrogenic diabetes insipidus. Molecular and Cellular Biology 20 5840-5846. (doi:10.1128/MCB.20.16.5840-5846.2000)

Holmes RS, Dulley JA \& Hilgers J 1982 Sorbitol dehydrogenase genetics in the mouse: a 'null' mutant in a 'European' C57BL strain. Animal Blood Groups and Biochemical Genetics 13 263-272. (doi:10.1111/j.13652052.1982.tb01569.x)

Hou ML, Huang SY, Lai YK \& Lee WC 2008 Geldanamycin augments nitric oxide production and promotes capacitation in boar spermatozoa. Animal Reproduction Science 104 56-68. (doi:10.1016/j.anireprosci. 2007.01.006)

Hugentobler SA, Humpherson PG, Leese HJ, Sreenan JM \& Morris DG 2008 Energy substrates in bovine oviduct and uterine fluid and blood plasma during the oestrous cycle. Molecular Reproduction and Development 75 496-503. (doi:10.1002/mrd.20760)

Kador PF, Kinoshita JH, Tung WH \& Chylack LT Jr 1980 Differences in the susceptibility of various aldose reductases to inhibition. II. Investigative Ophthalmology \& Visual Science 19 980-982.

Kaneko T, Iuchi Y, Takahashi M \& Fujii J 2003 Colocalization of polyolmetabolizing enzymes and immunological detection of fructated proteins in the female reproductive system of the rat. Histochemistry and Cell Biology 119 309-315.

Kawashima A, Osman BA, Takashima M, Kikuchi A, Kohchi S, Satoh E, Tamba M, Matsuda M \& Okamura N 2009 CABS1 is a novel calciumbinding protein specifically expressed in elongate spermatids of mice. Biology of Reproduction 80 1293-1304. (doi:10.1095/biolreprod.108. 073866)
Kinoshita JH \& Nishimura C 1988 The involvement of aldose reductase in diabetic complications. Diabetes/Metabolism Reviews 4 323-337. (doi:10.1002/dmr.5610040403)

Kobayashi T, Kaneko T, luchi Y, Matsuki S, Takahashi M, Sasagawa I, Nakada T \& Fujii J 2002 Localization and physiological implication of aldose reductase and sorbitol dehydrogenase in reproductive tracts and spermatozoa of male rats. Journal of Andrology 23 674-683.

de Lamirande E \& Gagnon C 2002 The extracellular signal-regulated kinase (ERK) pathway is involved in human sperm function and modulated by the superoxide anion. Molecular Human Reproduction 8 124-135. (doi:10.1093/molehr/8.2.124)

de Lamirande E \& Lamothe G 2009 Reactive oxygen-induced reactive oxygen formation during human sperm capacitation. Free Radical Biology \& Medicine 46 502-510. (doi:10.1016/j.freeradbiomed.2008. 11.004)

de Lamirande E \& O'Flaherty C 2008 Sperm activation: role of reactive oxygen species and kinases. Biochimica et Biophysica Acta 1784 106-115. (doi:10.1016/j.bbapap.2007.08.024)

de Lamirande E, Leclerc P \& Gagnon C 1997 Capacitation as a regulatory event that primes spermatozoa for the acrosome reaction and fertilization. Molecular Human Reproduction 3 175-194. (doi:10. 1093/molehr/3.3.175)

de Lamirande E, Lamothe G \& Villemure M 2009 Control of superoxide and nitric oxide formation during human sperm capacitation. Free Radical Biology \& Medicine 46 1420-1427. (doi:10.1016/j.freeradbiomed. 2009.02.022)

Larose J, Laflamme J, Côté I, Lapointe J, Frenette G, Sullivan R \& Bilodeau JF 2012 The polyol pathway in the bovine oviduct. Molecular Reproduction and Development 79 603-612. (doi:10.1002/mrd.22067)

Leclerc P, de Lamirande E \& Gagnon C 1996 Cyclic adenosine 3',5'monophosphate-dependent regulation of protein tyrosine phosphorylation in relation to human sperm capacitation and motility. Biology of Reproduction 55 684-692. (doi:10.1095/biolreprod55.3.684)

Lewis B \& Aitken RJ 2001 A redox-regulated tyrosine phosphorylation cascade in rat spermatozoa. Journal of Andrology 22 611-622.

Maas DH, Storey BT \& Mastroianni L Jr 1977 Hydrogen ion and carbon dioxide content of the oviductal fluid of the rhesus monkey (Macaca mulatta). Fertility and Sterility 28 981-985.

Mann T 1946 Studies on the metabolism of semen; fructose as a normal constituent of seminal plasma; site of formation and function of fructose in semen. Biochemical Journal 40 481-491.

Marin S, Chiang K, Bassilian S, Lee WN, Boros LG, Fernández-Novell JM, Centelles JJ, Medrano A, Rodriguez-Gil JE \& Cascante M 2003 Metabolic strategy of boar spermatozoa revealed by a metabolomic characterization. FEBS Letters 554 342-346. (doi:10.1016/S00145793(03)01185-2)

Marquez B \& Suarez SS 2004 Different signaling pathways in bovine sperm regulate capacitation and hyperactivation. Biology of Reproduction 70 1626-1633. (doi:10.1095/biolreprod.103.026476)

Matás C, Sansegundo M, Ruiz S, García-Vázquez FA, Gadea J, Romar R \& Coy P 2010 Sperm treatment affects capacitation parameters and penetration ability of ejaculated and epididymal boar spermatozoa. Theriogenology 74 1327-1340. (doi:10.1016/j.theriogenology. 2010.06.002)

Medrano A, García-Gil N, Ramió L, Montserrat Rivera $M$, FernándezNovell JM, Ramírez A, Peña A, Dolors Briz M, Pinart E, Concha II et al. 2006 Hexose-specificity of hexokinase and ADP-dependence of pyruvate kinase play important roles in the control of monosaccharide utilization in freshly diluted boar spermatozoa. Molecular Reproduction and Development 73 1179-1194. (doi:10.1002/mrd.20480)

Nayak RK \& Ellington EF 1977 Ultrastructural and ultracytochemical cyclic changes in the bovine uterine tube (oviduct) epithelium. American Journal of Veterinary Research 38 157-168.

Nichol R, Hunter RH, Gardner DK, Leese HJ \& Cooke GM 1992 Concentration of energy substrates in oviduvtal fluid and blood plasma of pigs during the peri-ovulatory period. Journal of Reproduction and Fertility 96 699-707. (doi:10.1530/jrf.0.0960699)

O'Flaherty C, de Lamirande E \& Gagnon C 2005 Reactive oxygen species and protein kinases modulate the level of phospho-MEK-like proteins during human sperm capacitation. Biology of Reproduction 73 94-105. (doi:10.1095/biolreprod.104.038794) 
O'Flaherty C, de Lamirande E \& Gagnon C 2006a Reactive oxygen species modulate independent protein phosphorylation pathways during human sperm capacitation. Free Radical Biology \& Medicine 40 1045-1055. (doi:10.1016/j.freeradbiomed.2005.10.055)

O'Flaherty C, de Lamirande E \& Gagnon C 2006b Positive role of reactive oxygen species in mammalian sperm capacitation: triggering and modulation of phosphorylation events. Free Radical Biology \& Medicine 41 528-540. (doi:10.1016/j.freeradbiomed.2006.04.027)

Osman BA, Kawashima A, Tamba M, Satoh E, Kato Y, Iki A, Konishi K, Matsuda M \& Okamura N 2011 Localization of a novel RNA-binding protein, SKIV2L2, to the nucleus in the round spermatids of mice. Journal of Reproduction and Development 57 457-467. (doi:10.1262/ jrd.10-179N)

Peterson RN \& Freund M 1970 Profile of glycolytic enzyme activities in human spermatozoa. Fertility and Sterility 21 151-158.

Pruneda A, Pinart E, Bonet S, Yeung CH \& Cooper TG 2006 Study of the polyol pathway in the porcine epididymis. Molecular Reproduction and Development 73 859-865. (doi:10.1002/mrd.20481)

Rodríguez-Martínez $\mathrm{H}$, Saravia $\mathrm{F}$, Wallgren $\mathrm{M}$, Tienthai $\mathrm{P}$, Johannisson $\mathrm{A}$, Vázquez JM, Martínez E, Roca J, Sanz L \& Calvete JJ 2005 Boar spermatozoa in the oviduct. Theriogenology 63 514-535. (doi:10.1016/ j.theriogenology.2004.09.028)

Roy SC \& Atreja SK 2008 Effect of reactive oxygen species on capacitation and associated protein tyrosine phosphorylation in buffalo (Bubalus bubalis) spermatozoa. Animal Reproduction Science 107 68-84. (doi:10.1016/j.anireprosci.2007.06.024)

Sabeur K \& Ball BA 2007 Characterization of NADPH oxidase 5 in equine testis and spermatozoa. Reproduction 134 263-270. (doi:10.1530/REP06-0120)

Salicioni AM, Platt MD, Wertheimer EV, Arcelay E, Allaire A, Sosnik J \& Visconti PE 2007 Signalling pathways involved in sperm capacitation. Society of Reproduction and Fertility Supplement 65 245-259.

Satake N, Elliott RM, Watson PF \& Holt WV 2006 Sperm selection and competition in pigs may be mediated by the differential motility activation and suppression of sperm subpopulations within the oviduct. Journal of Experimental Biology 209 1560-1572. (doi:10.1242/jeb. 02136)

Schmidt H \& Kamp G 2004 Induced hyperactivity in boar spermatozoa and its evaluation by computer-assisted sperm analysis. Reproduction 128 171-179. (doi:10.1530/rep.1.00153)

Srivastava SK, Hair GA \& Das B 1985 Activated and unactivated forms of human erythrocyte aldose reductase. PNAS 82 7222-7226. (doi:10. 1073/pnas.82.21.7222)

Suarez SS \& Ho HC 2003 Hyperactivated motility in sperm. Reproduction in Domestic Animals 38 119-124. (doi:10.1046/j.1439-0531.2003. 00397.x)

Sullivan R, Saez F, Girouard J \& Frenette G 2005 Role of exosomes in sperm maturation during the transit along the male reproductive tract Blood Cells, Molecules \& Diseases 35 1-10. (doi:10.1016/j.bcmd. 2005.03.005)

Tadokoro C, Yoshimoto $\mathrm{Y}$, Sakata M, Imai T, Yamaguchi M, Kurachi H, Oka Y, Maeda T \& Miyake A 1995 Expression and localization of glucose transporter 1 (GLUT1) in the rat oviduct: a possible supplier of glucose to embryo during early embryonic development. Biochemical and Biophysical Research Communications 214 1211-1218. (doi:10.1006/ bbrc.1995.2415)

Tajima Y, Okamura N \& Sugita Y 1987 The activating effects of bicarbonate on sperm motility and respiration at ejaculation. Biochimica et Biophysica Acta 924 519-529. (doi:10.1016/0304-4165(87)90168-1)

Tardif S, Laforest J-P, Cormier N \& Bailey JL 1999 The importance of porcine sperm parameters on fertility in vitro. Theriogenology $\mathbf{5 2}$ 447-459. (doi:10.1016/S0093-691X(99)00142-9)

Tardif S, Dubé C, Chevalier S \& Bailey JL 2001 Capacitation is associated with tyrosine phosphorylation and tyrosine kinase-like activity of pig sperm proteins. Biology of Reproduction 65 784-792. (doi:10.1095/ biolreprod65.3.784)

Vandeputte C, Guizon I, Genestie-Denis I, Vannier B \& Lorenzon G 1994 A microtiter plate assay for total glutathione and glutathione disulfide contents in cultured/isolated cells: performance study of a new miniaturized protocol. Cell Biology and Toxicology 10 415-421. (doi:10.1007/BF00755791)

Varma T, Liu SQ, West M, Thonhboonkerd V, Ruvolo PP, May WS \& Bhatnagar A 2003 Protein kinase C-dependent phosphorylation and mitochondrial translocation of aldose reductase. FEBS Letters $\mathbf{5 3 4}$ 175-179. (doi:10.1016/S0014-5793(02)03834-6)

Vecchio D, Neglia G, Di Palo R, Campanile G, Balestrieri ML, Giovane A, Killian G, Zicarelli L \& Gasparrini B 2010 lon, protein, phospholipid and energy substrate content of oviduct fluid during the oestrous cycle of buffalo (Bubalus bubalis). Reproduction in Domestic Animals 45 e32-e39. (doi:10.1111/j.1439-0531.2010.01662.x)

Vikramadithyan RK, Hu Y, Noh HL, Liang CP, Hallam K, Tall AR, Ramasamy R \& Goldberg IJ 2005 Human aldose reductase expression accelerates diabetic atherosclerosis in transgenic mice. Journal of Clinical Investigation 115 2434-2443. (doi:10.1172/JCl24819)

Visconti PE, Bailey JL, Moore GD, Pan D, Olds-Clarke P \& Kopf GS 1995 Capacitation of mouse spermatozoa. I. Correlation between the capacitation state and protein tyrosine phosphorylation. Development 121 1129-1137.

Visconti PE, Westbrook VA, Chertihin O, Demarco I, Sleight S \& Diekman AB 2002 Novel signaling pathways involved in sperm acquisition of fertilizing capacity. Journal of Reproductive Immunology 53 133-150. (doi:10.1016/S0165-0378(01)00103-6)

Wang WH, Abeydeera LR, Fraser LR \& Niwa K 1995 Functional analysis using chlortetracycline fluorescence and in vitro fertilization of frozenthawed ejaculated boar spermatozoa incubated in a protein-free chemically defined medium. Journal of Reproduction and Fertility 104 305-313. (doi:10.1530/jrf.0.1040305)

Yanagimachi R 1994 Mammalian fertilization. In The Physiology of Reproduction, 2nd edn, pp 189-317. Eds E Knobil\& JD Neill. New York: Raven Press.

Received 14 April 2014

First decision 7 May 2014

Revised manuscript received 15 July 2014

Accepted 21 July 2014 